ORIGINAL ARTICLE

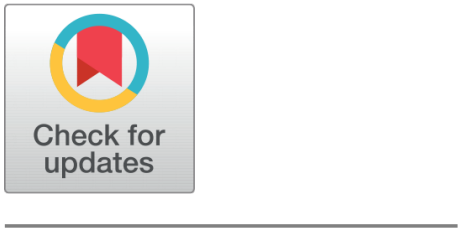

OPEN ACCESS

Received: 04.12.2019

Accepted: 31.12.2019

Published: 05.01.2020

Editor: Dr. D. R. Galfat

Citation: Ramprasath $\mathrm{P}$, Manikandan A, Prakasam K (2020) Role of llizarov's ring fixator for treatment of infected nonunion of Tibia. International Journal of Orthopaedics Traumatology \& Surgical Sciences 6(1): 86-89. https:// doi.org/10.47618/IJOTSS/v6i1.17

Corresponding author.

drmanikandanadimoolam@gmail.com

Funding: None

Competing Interests: None

Copyright: (c) 2020 Ramprasath et al. This is an open access article distributed under the terms of the Creative Commons Attribution License, which permits unrestricted use, distribution, and reproduction in any medium, provided the original author and source are credited.

Published By Society of Orthopaedics, Surgical and Dental Sciences

\section{ISSN}

Print: 2455-0809

Electronic: 2454-4167

\title{
Role of Ilizarov's ring fixator for treatment of infected nonunion of Tibia
}

\author{
P Ramprasath ${ }^{1}$, A Manikandan 2*, K Prakasam ${ }^{3}$ \\ 1 Associate Professor, Sri Lakshmi Narayana Institute of Medical Sciences, Puducherry \\ 2 Assistant professor, Sri Venkateshwaraa Medical College \& Research Institute, Puducherry \\ 3 Director and HOD, Dept of Orthopaedics, VMKVMC, Salem, India
}

\section{Abstract}

Infection is the most dreaded complication of the surgery and management of the infected non-union bones is also a challenging task. The aim of our study is to evaluate the efficacy of llizarov's ring fixator in the treatment with infected nonunion of tibia. 17 patients were included in our study. Rate of union was $100 \% .10$ patients had excellent results, 5 patients had good result and 2 patients had fair result. The minimal duration for union was 9 months with average duration lasting for 12 months. One patient needed a bone marrow injection at 2 month follow-up. Ilizarov ring fixator is an effective tool in treating Infection Non Union of Tibia and is a limb salvage procedure.

Keywords: Ilizarov's ring fixator; infected nonunion; tibia

\section{Introduction}

Infection is still one of the most dreaded complications of any surgery. Even though utmost precautions are taken, chance of infection cannot be ruled out in any orthopaedic procedure involving an implant. Closed fractures of tibia have comparatively less preva- lence of infection, with an incidence of $2.5 \%$. There is a 5-7 fold increase in infection when the primary trauma is associated with an open injury ${ }^{(1)}$. Such infection at the fracture can hamper the union leading to infected non union ${ }^{(2)}$. Management of such infected non union is challenging task.

Various modalities of management have been proposed in the past. Yet Ilizarov ring fixator has shown to provide very good treatment option for such infected non unions. It has also added advantages such as correction of deformities, regaining length in case of bone loss or shortening. Vascularity plays a major role in treatment of infection. With Ilizarov ring fixator vascularity could be increased with the help of corticotomy and also distraction osteogenesis ${ }^{(3-6)}$.

Even though Ilizarov fixator has many advantages, prolonged duration of treatment has been a main concern with this modality. This study was intended to evaluate the role of Ili- zov's ring fixator in treating infected non union.

AIM:

To study prospectively the efficacy of Ilizarov's ring fixator in the treatment of patients with infected nonunion of tibia.

\section{Methods}

Patients who presented to the outpatient department with sign of pus discharge and infection following a tibial 
fracture were screened. Patients fulfilling the inclusion criteria were selected and evaluated further. All routine blood investigations including TLC, CRP and ESR were also done prior to surgery. Radiological evaluation was done using Xray.

Wound swab from the discharge was sent for culture. Infected non union was classified us- ing G.S Kulkarni classification (table).

\begin{tabular}{ll}
\hline GS Kulkarni's classification of non union \\
\hline Type I & $\begin{array}{l}\text { Fragments in apposition with mild infection and } \\
\text { with or without implant }\end{array}$ \\
Type II & $\begin{array}{l}\text { Fragments in apposition with severe infection with } \\
\text { large or small wound }\end{array}$ \\
Type III & $\begin{array}{l}\text { Severe infection with a gap or deformity or shorten- } \\
\text { ing }\end{array}$ \\
IIIa & $\begin{array}{l}\text { Defect with loss of full circumference } \\
\text { IIIb }\end{array}$ \\
IIIc & Defect in $>1 / 3$ rd of cortex \\
\hline
\end{tabular}

The patients who were diagnosed to have infected non union of tibia were counseled and treated with Illizarov ring fixator during the period between Jan 2009 and October 2019. This included 17 patients, 7 females and 10 males. Mode of injury included RTA $(n=15)$ and fall from height $(n=2) .14$ patients had an open fracture as primary injury, which was treated initially with external fixation in 11 cases and primary internal fixation in 3 pa-tients. 3 patients had a closed fracture which got infected following internal fixation.

\section{Inclusion criteria:}

- Age 18-60 years

- Un united tibia shaft fractures with infection

- Duration of primary injury more than 4 months

\section{Exclusion criteria}

- Poly trauma/multiple fractures

- floating knee

- age $<18$ and $>60$ years

- patient with contraction of foot and ankle

- intra articular fractures

Pre operative culture was taken and started on appropriate antibiotics. Ilizarov frame was constructed prior surgery with the help of radiographs. Intra operatively, the previous hardware, if any were removed and fracture ends freshened. Thorough debridement of the non union site done with antibiotic lavage. Intra medullary reaming was also done wherever needed. Sclerotic bone from fracture ends was excised and freshened, aligned and stabilize with the ring fixator. Final adjustments were done using $\mathrm{C}$ Arm guidance. Fracture site were acutely docked and cortico cancellous bone grafting done. Corticotomy was done to help improve blood supply and to burn the infection when needed. one patient who had a short- ening of $>4 \mathrm{~cm}$, corticotomy and distraction osteogenesis was done.

Post operatively appropriate IV antibiotics was continued. Regular dressing and pin site care given. Patients were started on early weight bearing, knee and ankle ROM exercise.

Distraction of the corticotomy site was started on day 7 and same was taught to the patient. Patients were followed up on regular intervals were evaluated using ASAMI scoring system. Ring fixator was removed when good consolidation at the fracture site was noticed and cor-tical continuity in three of four cortex noted. Protective casting for the limb was done for 2 months following Ilizarov removal.

\section{Results}

In our study 17 patients were evaluated and no patients were lost in follow up. Patients were evaluated according to Association for the study and Application of the Method of Ilizarov (ASAMI) ${ }^{(7)}$. All 17 patients had full follow up. All patients had good union.

Rate of union was $100 \%$. As per ASAMI criteria, 10 patients had excellent results, 5 patients had good result and 2 patients had fair result. The minimal duration for union was 9 months with average duration lasting for 12 months. One patient needed a bone marrow in- jection at 2 month followup.

Table 1. ASAMI score - bone

\begin{tabular}{lll}
\hline RESULTS & DESCRIPTION & SCORE \\
\hline EXCELLENT & $\begin{array}{l}\text { Union, no infection, deformity }<7 \\
\text { degree, limb length discrepancy } \\
\end{array}$ & 10 \\
GOOD & $\begin{array}{l}\text { Union with any two of the following: } \\
\text { absence of infection, deformity }<7,\end{array}$ & 2 \\
& LLD $<2.5 \mathrm{CM}$ \\
FAIR & $\begin{array}{l}\text { Union with any one of the following: } \\
\text { absence of infection, deformity }<7,\end{array}$ & \\
& LLD $<2.5 \mathrm{CM}$ \\
POOR & $\begin{array}{l}\text { Non union/refracture/union+ infec- } \\
\text { tion+ deformity }>7+\text { LLD }>2.5\end{array}$ & 0 \\
\hline
\end{tabular}

Table 2. ASAMI score -functional results

\begin{tabular}{lll}
\hline RESULTS & DESCRIPTION & SCORE \\
\hline EXCELLENT & Active, no limp, minimal stiffness $<15$ & 6 \\
& loss, no RSD, insignificant pain \\
GOOD & $\begin{array}{l}\text { active, with one or two of the follow- } \\
\text { ing: limp, stiffness, RSD, signifi- cant } \\
\text { pain }\end{array}$ & 4 \\
\hline
\end{tabular}




\begin{tabular}{lll}
\hline RESULTS & DESCRIPTION & SCORE \\
\hline FAIR & $\begin{array}{l}\text { active, with three of the following: limp, } \\
\text { stiffness, RSD, significant pain }\end{array}$ & 2 \\
POOR & inactive & 0 \\
\hline
\end{tabular}

\section{COMPLICATIONS}

All patients had a successful union. One patient had a refracture due to a fall after complete union was achieved, after removal of the protective cast. Pin tract infection was a common complication with 14 patients having PTI. Infection settled with first debridement in all patients. One patient needed a bone marrow injection at 2 months, and united well at 1 year.
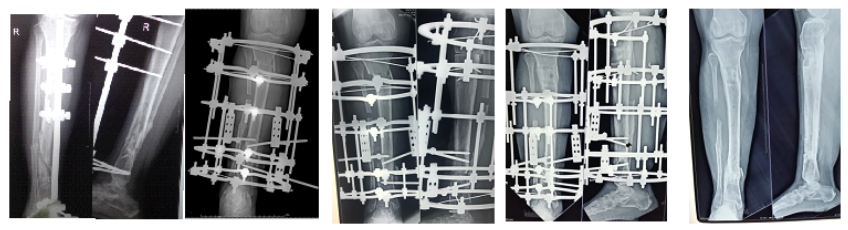

Fig 1. A 42 year old female, infected non union oftibia on external fixator treated with Ilizarov ring fixator, corticotomy and transport. Complete union achieved with correction of shortening
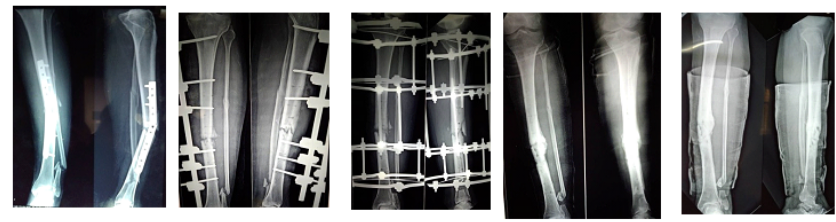

Fig 2. A 36 year old male, with infected tibia nonunion, implant failure, united well with Ilizarov ring fixator with bone grafting

\section{Discussion}

Failure of fracture union is the result of multiple factors affecting the union. This includes mechanical instability, bone loss, infection, osteoporosis, soft tissue damage and loss of blood supply ${ }^{(8)}$. Management of such fracture non union is itself difficult. Infected fracture non union, mainly involving the distal third of tibia is even more challenging to treat, because of the poor blood supply. Ilizarov technique is an effective tool in treating such infected non union.
Management of any infection needs thorough debridement of the local site. In case of a non union, a thorough debridement involves resection of the sclerotic bone ends and surrounding infected tissue. Culture sensitivity was sent for all patients. Most common organism was Staph Aureus. Culture was negative for 8 patients due to prior antibiotic course. This can sometime leave a bone defect at the fracture site. With Ilizarov technique this can be managed using distraction osteogenesis principle. Distraction osteogenesis has shown to be an effective treatment option in LLD and segmental fractures ${ }^{(9)}$.

Bone grafting plays an important role in treating non union. Vascularised bone grafts have been used successfully in treating infected non union ${ }^{(10)}$. Even though cortical grafts such as fibula can be used for bone defects, failure rate is high with fibular strut graft. Distraction osteogenesis again helps in such cases in regaining the limb length without sac- rificing the fibula ${ }^{(9)}$.

Illizarov fixator also helps in correction of deformity and shortening ${ }^{(11)}$. Early weight bearing and soft tissue management. Corticotomy has shown to be a good technique in improving the blood supply and is said to burn the infection by increasing the vascularity. Joint mobilization and weight bearing can be started early and minimize stiffness.

In our study, 10 patients (58\%) had excellent result. 5 patients $(30 \%)$ had good reddest and 2 patient (12\%) had fair result. This was comparable with other studies ${ }^{(12)}$. Pin tract infection was the common complication encountered involving 14 patients. The main prob- lem was counseling the patient during each visit about the prolonged treatment and pin site care. One patient, who had a good union, had a re fracture due to injury post removal of the protective cast. Patient was re-casted and managed conservatively.

\section{Conclusion}

Ilizarov ring fixator is an effective tool in treating Infection Non Union of Tibia and is a limb salvage procedure. The only downside is the duration of treatment (average of 9-12 months). Patients have to be counselled prior to surgery and regularly at every follow up in order to overcome this lengthy treatment time. Correction of deformity and regaining the length are again additional advantages. Ilizarov still is the best option available in these in- fected non unions.

\section{CONFLICT OF INTEREST}

The authors declare no conflicts of interest. 


\section{References}

1) Phieffer LS, Goulet JA. Delayed union of tibia (instruc- tional course lecture). J Bone Joint Surg Am 88-A. 2006;p. 205-216.

2) Frost HM. The biology of fracture healing; an overview for clinicians. Part II. Clin Orthop Relat Res. 1989;248:294-309.

3) Cattaneo R, Catagni M, Johnson EE. The treatment of infected nonunions and segmental defects of the tibia by the methods of Ilizarov. Clinical Orthopaedics and Related Research. 1992;\&NA;(280). Available from: https://dx.doi.org/10.1097/00003086-199207000-00017.

4) Paley D, Chandroy M, Pirone AM, Lentz P, Kantz D. Treatment of malunions and mal- nonunions of the femur and tibia by detailed preoperative planning and the Ilizarov technique. Or- thop Clin North Am. 1990;21:667-691.

5) [5]Ilizarov GA. Clinical application of the tension-stress effect for limb lengthening. Clinical Orthopaedics and Related Research. 1990;(250). Available from: https://dx.doi.org/10.1097/00003086199001000-00003.

6) Saleh M, Royston S. Management of nonunion of fractures by distraction with correction of angulation and shortening. The Journal of Bone and Joint Surgery British volume. 1996;78-B(1):105-109. Available from: https://dx.doi.org/10.1302/0301-620x.78b1.0780105.
7) Nonunion of the femur, in Operative Principles of Ilizarov fracture treatment, nonunion, osteomy- elitis, length- ening, deformity corrections. Maiocchi AB, Aronson J. Association for the Study and Application of the Methods of Ilizarov Group. 1991;p. 245-262.

8) DiPasquale D, Ochsner MG, Kelly AM, Maloney DM. The Ilizarov method for complex fracture nonunions. The Journal of Trauma: Injury, Infection, and Critical Care. 1994;37(4):629-634. Available from: https: //dx.doi.org/10.1097/00005373-199410000-00017.

9) Green SA, Jackson JM, Wall DM, Marrinow H, Ishkanian J. Management of Segmental Defects by the Ilizarov Intercalary Bone Transport Method. Clinical Orthopaedics and Related Research. 1992;(280). Available from: https://dx.doi.org/10.1097/00003086-199207000-00016.

10) Wood MB, Cooney WP, Irons GB. Skeletal reconstruction by vascularized bone transfer: Indications and results. Mayo Clinic Proceedings. 1985;60(11):729-734. Available from: https://dx.doi.org/ 10.1016/s0025-6196(12)60414-5.

11) Paley D, Catagni MA, Argnani F, Villa A, Benedetti GB, Cattaneo R. Ilizarov Treatment of Tibial Nonunions With Bone Loss. Clinical Orthopaedics and Related Research. 1989;(241):146-165. Available from: https://dx.doi.org/10.1097/00003086-198904000-00017.

12) Paley FB, Chirstianson D. An analysis of Illizarov and external fixators. Clin Orthop Relat Res. 1989;(241):195-195. 